\title{
Technological process of uniform distribution of fertilizers over the width of the coulter
}

\author{
Zafar Batirov*, Tura Razzakov, Fayzilla Begimkulov, and Farrukh Boymuratov \\ Karshi Engineering Economic Institute, Karshi, Uzbekistan
}

\begin{abstract}
The applied methods of applying fertilizers for cotton in Uzbekistan do not fully ensure the supply of nutrients to the plant's root system. The study aims to substantiate the technological process of uniform distribution of fertilizers in the root development zone and the parameters of coulters. When the fertilizer is distributed in the root development zone in tiers and the right ratio, the coefficient of their use increases, and the yield of cotton increases. The research uses the laws and rules of theoretical mechanics, mathematical statistics, mathematical planning of experiments, and the methods given in existing regulatory documents. The technology of forming new ridges instead of existing ridges and new furrows instead of existing furrows in fields with harvested husk with simultaneous fertilization and an improved chisel cultivator-fertilizer with comb-forming agents for its implementation, as well as the results of theoretical studies to substantiate the main parameters of the tuk coulter chisel-cultivator are presented.

The study determined the parameters of universal fertilizer Coulter chiselcultivator of fertilizer: the base cone of the diffuser in the form of an ellipse with minor axis width $10 \mathrm{~mm}$, height tool provider relative to the upper base of the truncated cone of $60 \mathrm{~mm}$, and a diameter of a half-cylinder of $20 \mathrm{~mm}$.
\end{abstract}

\section{Introduction}

In the world, the leading place is occupied by the development of technologies and technical means for tillage [1-23], sowing [25-26], harvesting crops [10], and their processing [12], including the application of mineral fertilizers in the layer of plant root development [31].

Technologies and technical means for applying mineral fertilizers to the development layer of the root system of plants are some of the important issues in the production of agricultural crops. One of the important tasks in agriculture is the development of technical means for the formation of ridges with the simultaneous introduction of mineral fertilizers in the zone of development of the root system of plants $[25,27,31]$. At the same time, much attention is paid to the development of combined machines that perform the technological processes of applying mineral fertilizers to the root system of plants during the preparation of the soil for sowing [25, 27, 31,36].

In the production of agricultural crops, special attention is paid to reducing labor and energy costs, saving resources based on advanced technologies, and developing highperformance agricultural machines.

* Corresponding author: botirov1972@inbox.ru 
One of the main ways to increase crop production is not the expansion of acreage, but a steady increase in yield, in which the rational use of fertilizers is essential [33-35].

The advanced farms of the republic have long proved the possibility of obtaining high and stable cotton yields with the systematic and correct use of mineral and organic fertilizers against the background of high agricultural technology. Effective use of increasing doses of mineral fertilizers from year to year is achieved in compliance with scientifically-based terms and norms of fertilizer application for certain soil and climatic conditions of cotton-growing areas.

The study aims to substantiate the technological process of uniform distribution of fertilizers in the root development zone and the parameters of coulters.

\section{Methods}

The research uses the laws and rules of theoretical mechanics, mathematical statistics, mathematical planning of experiments, as well as the methods given in existing regulatory documents. Preparation of the soil for sowing on the ridges can be carried out on cotton fields with a row spacing of 60 or $90 \mathrm{~cm}$. The installation of rippers in front of the coulters helps to reduce the traction resistance [8, 31-37].

In the spring, strip processing is carried out on the ridges and sow without fertilizing. As a result, scattered fertilization for plowing is excluded in the fall, early spring harrowing with malovanie, and the labor-intensive plowing operation with the formation turnover is replaced by non-fall loosening with fertilization. Ridges are formed simultaneously [31-37].

An improved chizel cultivator CHKU-4M carries out the proposed method. To do this, it is equipped with the following working bodies: rippers for loosening the soil in the row spacing, rippers with a pipeline for loosening existing ridges with simultaneous fertilization along the sowing line, and ridges for forming new ridges instead of existing ridges.

When working with the CHKU-4M chisel cultivator in production conditions, it was found that its coulter has significant drawbacks. After the passage of the coulter, a deep furrow is formed, it unloads the soil in front of it and has a large traction resistance. In addition, additional partitions quickly fail and the uniformity of the distribution of fertilizers along the width of the capture is violated [8, 31-37].

The study aims to substantiate the technological process of uniform distribution of fertilizers in the root development zone and the parameters of coulters. The research uses the laws and rules of theoretical mechanics, mathematical statistics, mathematical planning of experiments, as well as the methods given in existing regulatory documents. Preparation of the soil for sowing on the ridges can be carried out on cotton fields with a row spacing of 60 or $90 \mathrm{~cm}$. The installation of rippers in front of the coulters helps to reduce the traction resistance [31-37].

In the spring, strip processing is carried out on the ridges and sow without fertilizing. As a result, scattered fertilization for plowing is excluded in the fall, early spring harrowing with malovanie, and the labor-intensive plowing operation with the formation turnover is replaced by non-fall loosening with fertilization. Ridges are formed simultaneously [8, 3137].

An improved chisel cultivator CHKU-4M carries out the proposed method. To do this, it is equipped with the following working bodies: rippers for loosening the soil in the row spacing, rippers with a pipeline for loosening existing ridges with simultaneous fertilization along the sowing line, and ridges for forming new ridges instead of existing ridges.

When working with the CHKU-4M chisel cultivator in production conditions, it was found that its coulter has significant drawbacks. After the passage of the coulter, a deep furrow is formed; it unloads the soil in front of it and has a large traction resistance. In 
addition, additional partitions quickly fail, and the uniformity of the distribution of fertilizers along the width of the capture is violated [8, 31-37].

The study aims to substantiate the technological process of uniform distribution of fertilizers in the root development zone and the parameters of coulters.

\section{$3 \quad$ Results and Discussion}

The technological process of the proposed cone diffuser of the coulter is shown in Fig. 1. On the uniform distribution of the fat by the width of opener influenced by the following parameters: diameter of the cylinder (half-cylinder), the angle of tool provider relative to the horizontal $\left(\alpha_{1}\right)$, the distance from the lower edge of tool provider to the cylinder (11), the height of tool provider relative to the upper base of the truncated cone (h1) [31-37].

According to the results of preliminary studies and a priori data, the following levels and intervals of variation are accepted (Table.1) [34-36].

Table 1. Levels and intervals of variation of factors

\begin{tabular}{ccccc}
\hline The title of the factors & $\boldsymbol{T}_{\mathbf{1}}\left(\boldsymbol{x}_{\mathbf{1}}\right), \mathbf{m m}$ & $\boldsymbol{H}_{\mathbf{t}}\left(\boldsymbol{x}_{\mathbf{2}}\right), \mathbf{m m}$ & $\eta_{\mathbf{m}}\left(\boldsymbol{x}_{\mathbf{3}}\right)$, degree & $\boldsymbol{D}\left(\boldsymbol{x}_{\mathbf{4}}\right), \mathbf{m m}$ \\
\hline Basic level & 30 & 40 & 30 & 30 \\
Variation step & 10 & 20 & 15 & 10 \\
The upper level (+1) & 40 & 60 & 45 & 40 \\
The lower level (-1) & 20 & 20 & 15 & 20 \\
\hline
\end{tabular}

The experiments were carried out according to plan $B_{4}$ (as the most accurate plan is close to $D$ - optimal), on the stand. After processing the results of the experimental data, a regression equation was obtained that adequately describes the process of fertilizer distribution over the width of the coulter.

$$
\begin{aligned}
& y=19.62+2.24 X_{2}-4.12 X_{4}+1.33 X_{1} X_{2}+3.27 X_{1} X_{4}-1.82 X_{2} X_{3} \\
& -5.61 X_{2} X_{4}+6.52 X_{3} X_{4}+1.72 X_{1}^{2}+1.72 X_{2}^{2}+7.79 X_{3}^{2} .
\end{aligned}
$$

Analysis of equation (1) shows that the uniform distribution of fertilizer by the width of fertilizer Coulter greatest impact diameter of a half-cylinder $\left(X_{4}\right)$ and mounting height tool provider relative to the upper base of the truncated cone $\left(H_{1}\right)$. With an increase in the diameter of the semi-cylinder and with a decrease in the height of the installation of the pipeline, the uneven distribution of fertilizers decreases.

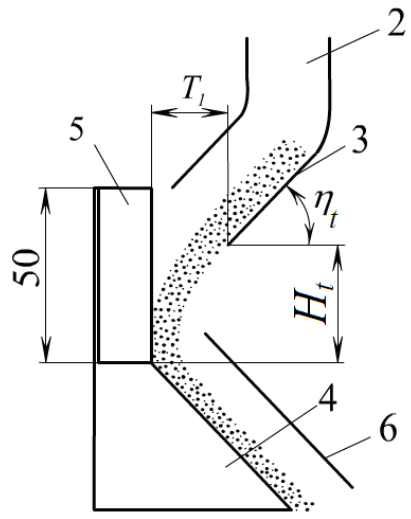

a)

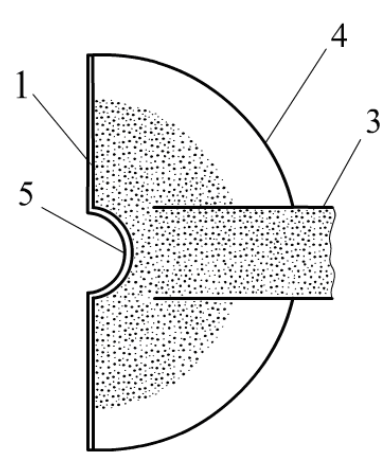

b)

Fig. 1. Technological scheme of the cone diffuser operation: $a$ is side view $b$ is a top view; 
1 is partition; 2 is take profit; 3 is feed part of tool provider; 4 is semi-cone; 5 is semi-cylinder; 6 is casing

It can be seen from equation (1) that the effects of factors $X_{1}$ (distance from the lower edge of the pipeline to the cylinder) and $X_{3}$ (the angle of inclination of the pipeline relative to the horizontal) were insignificant. The pair interactions and the values of the quadratic coefficients were significant.

To graphically interpret equation (1) and determine the degree of influence of factors $X_{1}$ and $X_{2}$, we consider a two-dimensional cross-section of the response surface.

Consider the change in the unevenness of the distribution of fertilizers over the width of the capture, depending on the factors $X_{1}$ and $X_{2}$ at $X_{3}=0, X_{4}=0$.

In this case, equation (1) takes the following form

$$
y=19,62+2,24 X_{2}+1,33 X_{1} X_{2}+1,72 X_{1}^{2}+1,72 X_{2}^{2} .
$$

We determine the coordinates of the center of the surface by differentiating equation (2) and solving the system of equations

$$
\begin{aligned}
\frac{\partial y}{\partial x_{1}}=1,33 X_{2}+3,46 X_{1} & =0, \\
\frac{\partial y}{\partial x_{2}} & =2.25+1.33 X_{1}+3.46 X_{2}=0,
\end{aligned}
$$

$X_{1}=0,27 ; X_{2}=-0,752$.

Substituting the values of $X_{1}$ and $X_{2}$ in equation (2), we get the value of the optimization criterion in the center of the surface $Y=18.778 \%$. Next, we perform a canonical transformation of equation (2), for which we solve the characteristic equation

$$
f(B)=\left|\begin{array}{cc}
1.72-B & 0.66 \\
0.66 & 1.72-B
\end{array}\right|=0
$$

and we get the eigenvalues (roots) of this characteristic equation, which turned out to be in $B_{11}=B_{22}=1.07$, and the equation itself took the following canonical form

$$
y-18,778=1,07 X_{11}^{2}+1,07 X_{22}^{2} \text {. }
$$

Determine the angle of rotation of the canonical axes $X_{1}{ }^{1}$ and $X_{2}{ }^{1}$ relative to the previous coordinates $x_{1}$ and $x_{2}$

$$
\operatorname{tg} \alpha=\frac{b_{12}}{b_{11}-b_{22}}=\frac{1.25}{1.72-1.72}=\frac{1.25}{0}=\infty .
$$

Substituting different values of unevenness in equation (5), we obtain the equations of the corresponding contour curves-circles, collectively representing a whole family of conjugate circles (lines of equal unevenness), which are shown in Fig.1.

Fig. 1 shows that with increasing height of the conductor relative to the upper base of the truncated cone, uneven seeding fertilizer by the width of fertilizer Coulter increases. The optimal values of the factors with the lowest unevenness (19\%) are: $P_{t}=20-32 \mathrm{~mm}$ and $E_{1}=30-36 \mathrm{~mm}$. 
Consider a two-dimensional cross-section of the response surface depending on the angle relative to the horizontal tool provider $\eta_{t}\left(x_{3}\right)$ and height of tool provider $H_{t}\left(x_{2}\right)$, which is shown in Fig.5.20. This cross-section is obtained for fixed values of the factors $T_{1}$ $=30 \mathrm{~mm} ; D=30 \mathrm{~mm}$. Analysis of this cross-section of the response surface shows that the minimum value of unevenness can be achieved with the following values of the factors:

$$
\eta_{t}=28-32^{\circ} \text { and } H_{t}=24-32 \mathrm{~mm}
$$

Consider a two-dimensional cross-section of the response surface, which characterizes the change in the uneven distribution of fertilizers depending on the distance from the lower edge of the pipeline to the cylinder $T_{1}\left(x_{1}\right)$ and the angle of inclination of the pipeline relative to the horizontal $\eta_{m}\left(x_{3}\right)$, which is a family of conjugate ellipses. It shows that the minimum value of the uneven distribution of fertilizers y at the zero level of the factors $H_{m}$ $=\left(x_{2}\right)$ and $D\left(x_{4}\right)$ is $20 \%$, and it is achieved at $T_{1}=26-34 \mathrm{~mm}, \eta_{t}=27-330$.

As can be seen from previous analyses, a two-dimensional cross-section of the response surface at a certain level of factors shows a change in the uneven distribution of fertilizers over the width of the coulter grip in this cross-section.

To determine the optimal values of the factors at which the least unevenness of the distribution of fertilizers is achieved, the equation is studied at a minimum on a computer. The following parameters of the coulter diffuser for broadband fertilization $L_{\mathrm{t}}=20 \mathrm{~mm}, h_{\mathrm{t}}$ $=60 \mathrm{~mm}, \alpha_{\mathrm{t}}=25^{\circ}$, and $D=20 \mathrm{~mm}$ were obtained.

\section{Conclusions}

1. The technology of forming new ridges instead of existing ridges and new furrows instead of existing furrows in fields with harvested husk with simultaneous fertilization and an improved chisel-cultivator-fertilizer with comb-forming agents for its implementation is justified.

2. The study determined the parameters of universal fertilizer Coulter chisel-cultivator of fertilizer: the base cone of the diffuser in the form of an ellipse with minor axis width $10 \mathrm{~mm}$, height tool provider relative to the upper base of the truncated cone of $60 \mathrm{~mm}$, and a diameter of a half-cylinder of $20 \mathrm{~mm}$.

\section{References}

1. Mamatov, F.M., Eshdavlatov, E., Suyunov, A. The Shape of the Mixing Chamber of the Continuous Mixer // Jour of Adv Research in Dynamical \& Control Systems, Vol. 12, 07-Special Issue, (2020). DOI: 10.5373/JARDCS/V12SP7/20202318 ISSN 1943$023 \mathrm{X}$.

2. Mamatov, F., Ergashev, I., Ochilov, S., Pardaev, X. Traction Resistance of Soil Submersibility Type "Paraplau" // Jour of Adv Research in Dynamical \& Control Systems, Vol.12, 07-Special Issue, (2020). DOI: 10.5373/JARDCS/V12SP7/20202336 ISSN1943-023X.

3. Aldoshin, N., Mamatov, F., Ismailov, I., Ergashov, G. Development of combined tillage tool for melon cultivation // 19th international scientific conference engineering for rural development Proceedings, Jelgava, 20. (2020). Volume 19. ISSN 1691-5976. DOI:10.22616/ERDev.2020.19.TF175.

4. Umurzakov, U., Mirzaev, B., Mamatov, F., Ravshanov, H., Kurbonov, S. A rationale of broach-plow's parameters of the ridge-stepped ploughing of slopes // XII International Scientific Conference on Agricultural Machinery Industry IOP Conf. 
Series: Earth and Environmental Science 403(2019) 012163 IOP Publishing doi:10.1088/1755-1315/403/1/012163.

5. Mirzaev, B., Mamatov, F., Chuyanov, D., Ravshanov, X., Shodmonov, G., Tavashov, $\mathrm{R}$ and Fayzullayev, X. Combined machine for preparing soil for cropping of melons and gourds // XII International Scientific Conference on Agricultural Machinery Industry. doi.org/10.1088/1755-1315/403/1/012158.

6. Mirzaev, B., Mamatov, F., Ergashev, I., Ravshanov, H., Mirzaxodjaev, Sh., Kurbanov, Sh., Kodirov, U and Ergashev, G. Effect of fragmentation and pacing at spot ploughing on dry soils // E3S Web of Conferences 97. doi.org/10.1051/e3sconf/201913501065.

7. Mamatov, F., Mirzaev, B., Shoumarova, M., Berdimuratov, P., Khodzhaev, D. Comb former parameters for a cotton seeder// International Journal of Engineering and Advanced Technology (IJEAT) Volume-9 Issue1 October/ DOI: 10.35940/ijeat.A2932.109119.

8. Mamatov, F., Mirzaev, B., Batirov, Z., Toshtemirov, S., Tursunov, O., Bobojonov, L. Justification of machine parameters for ridge forming with simultaneous application of fertilizers // CONMECHYDRO - (2020) IOP Conf. Series: Materials Science and Engineering 883(2020) 012165 IOP Publishing. doi:10.1088/1757899X/883/1/012165.

9. Mirzaev, B., Mamatov, F., Avazov, I., Mardonov, S. Technologies and technical means for anti-erosion differentiated soil treatment system// E3S Web of Conferences. doi.org/10.1051/e3sconf/20199705036.

10. Aldoshin, N., Didmanidze, O., Mirzayev, B., Mamatov, F. Harvesting of mixed crops by axial rotary combines // Proceeding of $7^{\text {th }}$ International Conference on Trends in Agricultural Engineering 2019. $17^{\text {th }}-20^{\text {th }}$ Prague, Czech Republic. - pp.20-26. September (2019)

11. Mirzaev, B., Mamatov, F., Aldoshin, N and Amonov, M. Anti-erosion two-stage tillage by ripper// Proceeding of 7th International Conference on Trends in Agricultural Engineering 17th-20th. Czech Republic. - pp.391-396. September (2019).

12. Mirzaev, B., Mamatov, F., Ergashev, I., Islomov, Yo., Toshtemirov, B., Tursunov O. Restoring degraded rangelands in Uzbekistan // Procedia Environmental Science, № 6. - pp 395-404. (2019).

13. Uzakov, Z.U., Mamatov, F.M., Begulov, O. Implementation of object-oriented Programming technology in the one-dimensional oil displacement problem // International Conference on information Science and Communications Technologies: ICISCT 2019/0012008. Tashkent, Uzbekistan. INSPEC Accession Number: 19412491. DOI: 10.1109/ICISCT47635.2019.9012008.

14. Mamatov, F., Mirzaev, B., Berdimuratov, P., Turkmenov, Kh., Muratov, L., Eshchanova, G. The stability stroke of cotton seeder moulder // CONMECHYDRO (2020). IOP Conf. Series: Materials Science and Engineering 883 (2020) 012145 IOP Publishing. doi:10.1088/1757-899X/883/1/012145.

15. Mamatov, F., Mirzaev, B., Tursunov, O. A Justification of Broach-Plow's Parameters of the Ridge-Stepped Ploughing // E3S Web of Conferences 97, 05035 (2019). doi.org/10.1051/e3sconf/20199705035.

16. Ahmedov, B.J., Mirzaev, B.S.,Mamatov, F.M., Khodzhaev, D.A., Julliev, M.K. Integrating of gis and gps for ionospheric perturbations in d- And f-layers using vlf receiver // InterCarto, InterGIS 26, - c. 547-560. DOI: 10.35595/2414-9179-2020-1-26547-560.

17. Mamatov, F., Mirzaev, B., Tursunov, O., Ochilov, S and Chorieva, D. Relief, physicomechanical and technological properties of soil in the cotton growing area // ICECAE (2020). IOP Conf. Series: Earth and Environmental Science 614(2020) 012169. IOP Publishing. doi:10.1088/1755-1315/614/1/012169. 
18. Shamsutdinov, Z., Ubaydullaev, Sh., Shamsutdinov, N., Mirzaev, B., Mamatov, F., and Chorshabiyev, N. The concept of the phytogenic field: theory, research experience and practical significance // ICECAE (2020). IOP Conf. Series: Earth and Environmental Science 614(2020) 012164. IOP Publishing. doi:10.1088/1755-1315/614/1/012164.

19. Umurzakov, U., Mamatov, F., Aldoshin, N., and Mirzaev, B. Exploration of tillage technologies in the Republic of Uzbekistan // ICECAE (2020) IOP Conf. Series: Earth and Environmental Science 614(2020) 012168. IOP Publishing. doi:10.1088/1755$1315 / 614 / 1 / 012168$.

20. Mamatov, F., Aldoshin, N., Mirzaev, B., Ravshanov, H., Kurbanov, Sh and Rashidov, N. Development of a frontal plow for smooth, furless plowing with cutoffs // IPICSE (2020). IOP Conf. Series: Materials Science and Engineering 1030 (2021) 012135 IOP Publishing. doi:10.1088/1757-899X/1030/1/012135.

21. Mamatov, F., Mirzaev, B., Mirzahodzhaev, Sh., Uzakov, Z and Choriyeva, D. Development of a front plow with active and passive working bodies // IPICSE (2020). IOP Conf. Series: Materials Science and Engineering 1030 (2021) 012164. IOP Publishing. doi:10.1088/1757-899X/1030/1/012164.

22. Mamato, F.M., Eshdavlatov, E., Suyuno, A. Continuous Feed Mixer Performance //Journal of Advanced Research in Dynamical and Control Systems (JARDCS). Volume-12, 07-Spesia1 Issue, (2020). DOI: 10.5373/JARDCS/V12SP7/20202343. ISSN 1943-023X.

23. Mamatov, F., Ergashev, I., Mirzaev, B., Pardaev, X, Chorieva, D. Research of the Penetration Process of the Frontal Plow // 2nd Bukittinggi International Conference on Education (BICED) 2020. Journal of Physics: Conference Series 1779 (2021) 012002. IOP Publishing. doi:10.1088/1742-6596/1779/1/012002.

24. Kodirov, U., Aldoshin, N., Ubaydullayev, Sh., Sharipov, E., Muqimov, Z and Tulaganov, B. The soil preparation machine for seeding potatoes on comb // CONMECHYDRO - (2020) IOP Conf. Series: Materials Science and Engineering 883(2020) 012143 IOP Publishing doi:10.1088/1757-899X/883/1/012143.

25. Ravshanov, Kh., Fayzullaev, Kh., Ismoilov, I., Irgashev, D., Mamatov, S. The machine for the preparation of the soil in sowing of plow crops under film // CONMECHYDRO - (2020) IOP Conf. Series: Materials Science and Engineering 883(2020) 012138 IOP Publishing doi:10.1088/1757-899X/883/1/012138.

26. Ravshanov, H, Babajanov, L, Kuziev, Sh, Rashidov, N, Kurbanov, Sh. Plough hitch parameters for smooth tails// CONMECHYDRO - (2020) IOP Conf. Series: Materials Science and Engineering 883(2020) 012139 IOP Publishing doi:10.1088/1757899X/883/1/012139.

27. Chuyanov, D., Shodmonov, G.,Avazov, I., Rashidov, N, Ochilov, S. Soil preparation machine parameters for the cultivation of cucurbitaceous crops // CONMECHYDRO - (2020) IOP Conf. Series: Materials Science and Engineering 883(2020) 012139 IOP Publishing doi:10.1088/1757-899X/883/1/012122.

28. Mamatov F.M., Mirzaev B.S., Avazov I.Zh.. Agrotehnicheskie osnovy sozdanija protivojerozionnyh vlagosberegajushhih tehnicheskih sredstv obrabotki pochvy $\mathrm{v}$ uslovijah Uzbekistana // - Prirodoobustrojstvo, [In Russian]. (2014).

29. Mamatov F.M., Mirzaev B.S. Erosion preventive technology of crested ladder-shaped tillage and plow design // European Applied Sciences. Stuttgart (Germany), - pp. 7173. (2014).

30. Lobachevskij Ja.P., Mamatov F., Jergashev I.T. Frontal'nyj plug dlja hlopkovodstva // - Hlopok, № 6.- 35-37 str. [In Russian]. (1991).

31. Mamatov F.M., Batirov Z.L., Khalilov M.S., Kholiyarov J.B. Three-Tiered Fertilizer Application with a Spreading Funnel of a Subsoil Tiller. Agricultural Machinery and 
Technologies. (2019);13(4):48-53. (In Russ.) doi: 10.22314/2073-7599-2019-13-4-4853.

32. Lichman G.I., Lichman A.A. Assessment of the impact of fertilizer application on crop yields. N5. 16-21. [In Russian]. (2017).

33. Batirov Z., Toirov I., Boymuratov F., Sharipov Sh. Layered application of mineral fertilizers with the coulter ripper of a combined unit//IOP Conf. Series: Materials Science and Engineering 1030 (2021).doi: 10.1088/1757-899X/1030/1/012168.

34. Mamatov F., Mirzaev B., Batirov Z., Toshtemirov S., Tursunov O., Bobojonov L. Justification of machine parameters for ridge forming with simultaneous application of fertilizers. //IOP Conf. Series: Materials Science and Engineering 883 (2020). IOP Publishing doi:10.1088/1757-899X/883/1/012165

35. Mamatov F.M., Batirov Z.L, Xalilov M.S.Chizel-cultivator fertilizer for forming ridges and applying fertilizers. European Sciences review scientific journal. - №3-4. - P. 267270. (2018).

36. Mamatov F.M., Kodirov U.I. Energy-recourse machine for preparing soil for planting root crops on ridges. European Science Review.Vienna, N11. 125-126. (2016).

37. Ahmetov A.A., Atakulov H.K., Allanazarov M.A., Inojatov I.A., Nurmihamedov B.U., Uzakbergenov $\mathrm{Zh}$. K. Comprehensive research on the creation of combined tillage machines. 154. [In Russian]. Buhoro. (2012). 